\title{
Psicologia e Pós-Verdade: a Emergência da Subjetividade Digital
}

\author{
Psicología y Post-Verdad: la Emergencia de la Subjetividad Digital \\ Psychology and Post-Truth: the Emergence of Digital Subjectivity
}

\author{
Pedrinho Guareschi \\ ORCID: http://orcid.org/0000-0003-0875-5865 \\ Universidade Federal do Rio Grande do Sul - Rio Grande do Sul/Brasil
}

\section{Resumo}

A partir de uma análise crítica do que se entende por Pós-verdade, o trabalho discute dois pontos interligados. No primeiro investiga o importante papel que a Psicologia está desempenhando dentro de uma nova ambiência sócio-antropológica, com repercussões políticas e, principalmente, econômicas. O segundo ponto detém-se no aprofundamento do conceito de subjetividade. Mostra como estão sendo atingidas, com o predomínio do tecnoliberalismo que faz uso das novas mídias, diferentes dimensões do ser humano. Esse processo propicia a construção de uma nova subjetividade, que poderia ser denominada de subjetividade digital. A investigação procura evidenciar que na implementação dessas práticas midiáticas é o próprio ser humano que está sendo objeto de manipulação. Aprofunda-se a administração digital da vida humana que vai sendo transformada num novo objeto de consumo. As novas mídias procuram atingir todas as sequências da vivência do ser humano produzindo uma mercantilização integral da vida.

Palavras-chave: Psicologia e pós-verdade; Subjetividade digital; Algoritmo; Tecnoliberalismo.

\section{Resumen}

A partir de un análisis crítico de lo que se entiende por Post-verdad, el trabajo discute dos puntos interconectados. En el primero, investiga el importante papel que la Psicología está desempeñando en un nuevo ambiente socio-antropológico, con repercusiones políticas y, principalmente, económicas. El segundo punto se detiene en la profundización del concepto de subjetividad. Muestra cómo están siendo alcanzadas, con el predominio del tecnoliberalismo que hace uso de los nuevos medios, diferentes dimensiones del ser humano. Este proceso propicia la construcción de una nueva subjetividad, que podría ser denominada de subjetividad digital. La investigación busca evidenciar que, en la implementación de esas prácticas mediáticas, es el propio ser humano que está se tornando objeto de manipulación. Se profundiza la administración digital de la vida humana que va transformándose en un nuevo objeto de consumo. Los nuevos medios buscan alcanzar todas las secuencias de la vivencia del ser humano produciendo una mercantilización integral de la vida.

Palabras clave: Psicología y post-verdad; Subjetividad digital; Algoritmo; Tecnoliberalismo.

\begin{abstract}
Through a critical analysis known as Post-truth, this paper discusses two interconnected themes. The first one investigates the important role that psychology plays in the recent socio-anthropological environment and its main political and economic repercussions. The second theme explains the concept of subjectivity and how different dimensions of the human beings are influenced with the preponderance of technoliberalism and the new medias. This new process propitiates the construction
\end{abstract}


of a new kind of subjectivity, which could be named as digital subjectivity. The investigation also reveals that the implementation of these media practices manipulates the human being itself. The digital administration of human life transforms itself into a new object of consumption. The new media seek to comprise all the sequences of the human experience, which results in the commodification of the whole life

Keywords: Psychology and post-truth; Digital subjectivity; Algorithm; Technoliberalism.

\section{Introdução}

O objetivo desse artigo é refletir sobre novos papéis que a Psicologia está assumindo principalmente nos momentos surpreendentes do aparecimento de novas formas de comunicação ligadas ao que se denominou chamar de Pós-verdade. O emprego da Psicologia tem-se tornado peça fundamental nas novas estratégias de ação política, militar e, principalmente, econômica. A dominação econômica, através do capitalismo financeiro internacional, os conflitos políticos e até mesmo as guerras que se travam entre países, não podem prescindir da Psicologia. Nesse contexto, o papel da Psicologia se coloca fundamentalmente naquele espaço onde se dá a criação e reprodução do que é considerado realidade, por um lado; e, por outro, na legitimação e sustentação das relações que, a partir da realidade construída, se pretendem hegemônicas e dominantes. O novo mundo que se abriu com as novas mídias necessita cada vez mais dos recursos da Psicologia.

Antes, contudo, de enfrentar os objetivos de nossa empreitada, julgo oportuno apresentar algumas considerações introdutórias sobre o fenômeno da comunicação. Ao falarmos em comunicação é sempre ilustrativo relembrar sua trajetória, principalmente a partir do que se chamou de virada linguística, até chegar a esse momento de Pós-verdade. Não deixa de ser um fato que a comunicação, entendida tanto como uma relação entre pessoas, ou como materialização de expressões símbolos, existe desde o início da humanidade como podemos deduzir das pesquisas sobre a origem dos humanos: inscrições, pinturas etc. Sua materialização se fez de muitas maneiras, com inúmeros alfabetos. Uma característica, contudo, que acompanhou o fenômeno da comunicação e que, nos assusta nos dias de hoje, é o fato de ela ter o papel de substituir mensagens e significados. Também, teve sempre de arcar com um problema: qual a relação entre esses símbolos e mensagens com aquilo que eles querem significar e expressar?

Poderíamos dizer que essa é a dialética que acompanha a história da comunicação desde que o ser humano iniciou sua situação de partilha com outros. Ela foi sendo enfrentada e trabalhada, e se reapresenta nos dias de hoje sob formas surpreendentes, que para alguns se constitui até mesmo numa nova era: a era da Pós-verdade.

Pode-se ainda considerar nessa misteriosa e desafiadora trajetória da comunicação através dos séculos que, se por um lado ela subsiste como um elemento imaterial, representacional, cuja principal finalidade seria supostamente poder dar conta e nos colocar em sintonia com o lá fora; por outro lado, ela serve também ao propósito de ocultar, negar ou falsificar, através de seus elementos constitutivos - o emprego de signos, significantes, significados e símbolos de todo o tipo - esse próprio lá fora. Ao não levarmos em conta a dimensão da ética e permanecermos apenas na semiótica, corremos o risco de, conforme assinala Eco (1976) com certa ironia, "semiótica é, em princípio, a disciplina que estuda tudo que pode ser usado para mentir" (p. 7).

Houve um tempo em que a palavra valia um número: a época da modernidade e do positivismo lógico. Depois veio a virada linguística e Wittgenstein (1992) que, literalmente, virou a mesa com sua poderosa afirmação, que nos deixa atônitos até hoje: "Os limites da minha linguagem significam os 
limites do meu mundo" (p. 74). E a partir daí ninguém mais descansou. Remeto para o estudo de Amon e Idiart (2017), uma excelente análise histórica, provocativa e ilustrativa da caminhada da comunicação. Ela nos possibilita estabelecer uma análise crítica desses novos tempos, precursores desse novo fenômeno denominado de Pós-verdade.

Estamos diante de paradoxos surpreendentes. A objetividade, como ideal da ciência moderna, com a palavra medida, objetificada, transformara-se, como sugeriu Barthes (2011), em uma impostura. Poderíamos nos questionar: será que a Pós-verdade não seria uma reação? Se os signos podem ser usados para dizer uma mentira, tanto quanto uma verdade (Eco, 1976), é interessante, para os estudiosos, perguntar: que efeitos podem decorrer desta liberdade? "Se os limites do meu mundo são os limites da minha linguagem" (Wittgenstein, 1992, p. 74), a Pós-verdade, como uma indiferença aos fatos, não seria um adjetivo de um mundo sem verdade e sem mentira, de um mundo sem limites éticos?

Como resposta ao objetivo proposto, vou deter-me e aprofundar dois pontos que julgo centrais: 1 . Discuto aqui o que se pode entender por Pós-verdade e como a Psicologia está se prestando a legitimar e fortificar as características dessa nova ambiência social. 2. Nesta parte, desafio os leitores para uma discussão bem mais séria e provocativa, que carrega consigo ressonâncias profundamente éticas: estaria sendo construída uma nova subjetividade, uma subjetividade digital, que pode transformar os humanos em objetos de consumo no horizonte de um tecnocapitalismo financeiro internacional?

\section{Pós-verdade e psicologia}

\section{Pós-verdade: um fenômeno desafiador}

Inicialmente, faço uma discussão crítica sobre o que, dentre inúmeras aproximações e noções, considero melhor chamar de fenômeno da Pós-verdade, para depois relacioná-lo com o mundo da Psicologia. Interessante o termo fenômeno. Dele se originou e instituiu até mesmo toda uma perspectiva teórica $\mathrm{e}$ metodológica, a fenomenologia. Kant procurou distinguir entre phainomenon (o que se poderia observar), e noumenon, o que não poderia ser atingido. Outros pensaram essa relação na dimensão do que muitos analistas chamam de mistério, a investigação contínua que nos leva ao entendimento sempre mais aprofundado de algo que, analogamente, seria o que denominamos hoje fenômeno, isto é, uma manifestação, um sinal que nos leva sempre mais adiante, uma espécie de horizonte: ao pensarmos tê-lo atingido, ele se apresenta sob novos ângulos e novas compreensões. Como veremos adiante, parece não ser fora de propósito pensar a Pós-verdade como fenômeno.

Como sabemos, Pós-verdade foi a palavra do ano, eleita em 2016 pelo Oxford Dictionaries. Empresto da introdução do primeiro artigo do livro Psicologia, Comunicação e Pós-Verdade (Guareschi, Amon, \& Guerra, 2017), algumas informações e dados recolhidos e apresentados pela pesquisa de Amon (2017). Na escolha da palavra do ano, o dicionário não exige que a palavra seja nova, mas que tenha chamado a atenção e que tenha tido impacto no último ano e que se tenha popularizado em nível mundial. Pós-verdade é "um adjetivo definido como relativo a, ou denotando circunstâncias nas quais fatos objetivos têm menos influência na formação da opinião pública do que apelos à emoção e às crenças pessoais" (English Oxford Living Dictionaries, s.d., Word of the Year 2016 is..., para.1, nossa tradução) ${ }^{1}$. O próprio dicionário, ao explicar por que a palavra tinha sido escolhida, diz que ele pode aparecer associado a um substantivo específico, como na expressão política pós-verdade (English Oxford Living Dictionaries, s.d., Why Was This Chosen?,

\footnotetext{
1 an adjective defined as 'relating to or denoting circumstances in which objective facts are less influential in shaping public opinion than appeals to emotion and personal belief'
} 
para.1), ou mesmo, a partir do significado que o prefixo pós pode assumir, referir-se a toda uma era: a era da Pós-verdade (Oxford Living Dictionaries, s.d., A Brief History of PostTruth, para.1).

Seja como for, o importante é que as discussões sobre o fenômeno Pós-verdade vêm mostrando, e até certo ponto demonstrando, que aquilo que era considerado sólido, está sendo fragilizado e se tornando líquido. Há, junto com essa dissolução do que era considerado verdade, concomitantemente uma aceitação gradual do que era considerado mentira. Em seu ensaio, Guerra e Barbosa (2017) apresentam uma discussão muito perspicaz e pertinente desse novo fenômeno. Procuram descrevê-lo, e em parte conceituá-lo, como uma nova ambiência social, uma ontoepistemologia, implicando naquilo que de mais profundo pode haver numa sociedade, o seu ethos. Poder-se-ia entendê-lo como uma espécie de Zeitgeist, constituindo-se quase como uma nova cosmovisão.

Ralph Keyes (2004) já empregou a expressão no título de um de seus livros, The Post Truth Era - Dishonesty and Deception in Contemporary Life. E ele o emprega como adjetivo, como em Era Pós-verdade. Mostra, assim, como a mentira vem sendo cada vez mais suavizada e o ato de mentir vai perdendo seu estigma negativo. Quando alguém mente, há reações do tipo "foi com boas intenções", "quem sou eu para julgar", ou até mesmo "o que é verdade, afinal?" Vai-se formando uma nova ética, que passa a ser chamada de ética alternativa (alt.ethics, Keyes, 2004, p.19), mais maleável, com nuances, escalas, graus de honestidade. A era pós-verdade abre espaço, então, para uma banalização da mentira.

Em 2004, Eric Alterman cunhou o termo presidência pós-verdade, empregando também o termo como adjetivo, em que mostra as inúmeras mentiras presidenciais e a erosão da confiança pública da figura dos governantes. Documenta suas afirmações com fatos $e$ exemplos de quatro presidentes dos EUA onde se verificaram afirmações e posturas mentirosas, mas que no momento, ajudados muitas vezes pela mídia, foram sendo colocadas como verdades, que só mais tarde foram desmascarados (Guerra \& Barbosa, 2017).

Como veremos adiante, creio ser importante ressaltar aqui um fator relevante, que nos ajudará a entender esse surpreendente fenômeno de aceitação de fatos mentirosos e artifícios de enganação. Por um lado, existe a distorção dos fatos; mas o que realmente surpreende é a indiferença em relação a essa distorção. Desde o momento em que o fato, verdadeiro ou não, se encaixe com as crenças do indivíduo, ele passa a ser aceito e válido para os telespectadores, ouvintes ou leitores. Como afirmou Priolli, a Pós-verdade "não seria [...] o culto à mentira, mas a indiferença com a verdade dos fatos. Eles podem ou não existir, e terem ocorrido ou não da forma divulgada, que tanto faz para os indivíduos" (Priolli, 2017, para.4); mas se ele vem ao encontro do que a pessoa pensa, de suas crenças e desejos, ela passa a aceitá-lo.

O escritor Homero Reis, partindo do conceito de realidade líquida, mundo líquido de Bauman, em que ele analisa como as relações entre as pessoas tendem a ser menos frequentes e menos duradouras, comenta: "a insegurança torna-se parte estrutural da constituição do sujeito pós-moderno" (2017, para.1). "No mundo pós-moderno a quantidade de informação é absurdamente grande, enquanto a formação e a reflexão são reduzidas ao mínimo" (Reis, 2017, para 5). O próprio Bauman, numa entrevista a Ricardo de Querol do El País, afirma que "estamos em um estado de interregno entre uma etapa em que tínhamos certezas e outra em que a velha forma de atuar já não funciona". (2016, para.10). Segundo Bauman, as certezas foram abolidas. São criadas bolhas ideológicas, e com isso deixamos de dialogar com opiniões diferentes das nossas. "Quando alguém publica algo que não nos agrade, simplesmente deletamos essa pessoa. Dessa maneira elas são utilizadas para corroborar nossas próprias opiniões" (Guerra \& Barbosa, 2017, p.130). 
Com o que vimos discutindo, podemos entrever que a palavra Pós-verdade parece indicar não tanto um substantivo, mas principalmente um adjetivo, um estado de indiferença e descaso. Verifica-se uma guerra de ideias, em que tudo passa a valer conforme os interesses, desejos, crenças e convicções pessoais. Cria sentido, nesse contexto, a afirmação de Harford (2017, para. 48) de que "na guerra das ideias, o tédio e a distração constituem armas poderosas". Estaríamos entrando numa nova era?

Se a história vier a dizer que estamos realmente vivendo uma nova era, esta não será a era da Pós-verdade, mas uma Era Pós-verdade. O mais relevante dessa peculiaridade é que o fenômeno Pós-verdade não seria algo que estaria entre nós, mas seria o próprio entre (Guareschi et al., 2017, p.15).

Por isso, essa realidade se coloca como algo difícil de ser compreendido, agarrado e domado. $\mathrm{E}$ isso, como vimos, desperta certa angústia. Passamos a refletir como a Psicologia, diante de tais situações, foi sendo procurada, que tarefas passou a desempenhar e para que fins.

\section{O papel da Psicologia}

Diante desse fenômeno da Pós-verdade vamos descobrindo, com muita surpresa, uma íntima relação com o campo da Psicologia. É dentro do espaço psicológico que esse fenômeno passa a ser frequente e onde ele vai buscar recursos para sua operacionalização.

Ao examinar com atenção a definição que o Dicionário de Oxford oferece para Pósverdade, damo-nos conta de imediato da presença de inúmeros termos que constituem o campo da Psicologia, ou remetem a sua área de reflexão. No entender do Dicionário, a dimensão psicológica está intrinsecamente ligada ao conceito. Ressaltamos, principalmente, expressões como apelos à emoção e crenças pessoais; e influência em moldar a opinião pública.
Ao falar da Psicologia estamos, fundamentalmente, nos referindo àquela dimensão do ser humano que responde ao nosso mundo mental, representacional, simbólico: nosso psiquismo jamais conseguiu alguém dar conta dessa misteriosa relação entre o biológico e o psíquico, revelado no mito fundante da humanidade, mito da Esfinge. Referimo-nos às partes dessa relação como mente e corpo, dimensões psíquicas e biológicas, por motivos didáticos. Não presumimos uma separação entre essas dimensões. Pelo contrário, reconhecemos sua intrínseca relação. É à parte dessa relação que costuma ser denominado de psíquica a que nos referimos. No que segue vamos nos deter em alguns conceitos do campo da Psicologia que nos ajudarão na argumentação que pretendemos oferecer sobre Psicologia e Pós-verdade.

A questão geradora que nos guia é a seguinte: por que as pessoas fazem o que fazem? Em toda situação, o que interessa sempre é examinar as razões da existência das pessoas e suas consequentes ações e comportamentos. Se formos examinar as inúmeras teorias que se situam no campo da Psicologia, constataremos que todas elas procuram aprofundar essas questões. Evidentemente, há sempre alguma razão para fazemos o que fazemos. Nem sempre se pode garantir que as pessoas estejam conscientes do que fazem. Apenas quando elas param e fazem a pergunta "por que estou fazendo isso que estou fazendo?" é que elas vão tomando consciência de seus atos (explicitamos abaixo o que entenderemos por consciência).

Nossos intentos, com essas reflexões sobre o fenômeno que passou a ser denominado de Pós-verdade, numa era de crescentes e desafiadoras novas tecnologias, é continuar a refletir sobre novas perguntas. Para nossos propósitos de relacionar a Pós-verdade com a Psicologia vamos nos concentrar em alguns conceitos que poderão ajudar na aproximação desse fenômeno: valores, crenças, motivações; consciência; e produção de subjetividades.

Valores, crenças, motivações 
Apesar de ser possível identificar pequenas conotações que podem diferenciar os dois termos, como comumente utilizados na linguagem cotidiana, vamos discuti-los aqui conjuntamente. Valor, em sua etimologia, do latim, valere, significa estar bem, ter peso. Evidentemente, não um peso físico, mas um peso afetivo, ético. Certamente, as crenças de cada pessoa são, para elas, valores e os valores, sem que nos demos conta, se transformam em crenças.

Essas são realidades profundamente presentes em cada pessoa e ao mesmo tempo extremamente misteriosas. Fazem parte daquilo que discutíamos acima e que denominamos de psiquismo. Na análise dessa dimensão psíquica, os valores são, muitas vezes, considerados como ligados a uma dimensão específica desse psiquismo que se manifesta através dos afetos e emoções das pessoas; essa dimensão afetiva é contraposta, por muitos. A outra dimensão que também faz parte de nosso psiquismo, é denominada de lógica, racional, cognitiva. Não aderimos, contudo, à tese de que se possa separar o cognitivo do afetivo, como muito bem mostra Jovchelovitch (2007). Numa reflexão perspicaz e profunda ela mostra como nosso mundo psíquico, isto é, nossas representações, cognições, valores, crenças, afetos, etc. constituem um todo, onde essas dimensões estão intrinsecamente interligadas.

Caminham nessa linha os comentários de Moscovici. Quando perguntado sobre o que entendia por crença, ele afirma:

[...] duvido que possamos realmente compreender a vida mental dos indivíduos ou grupos, se nós menosprezamos o cruzamento híbrido de fé e conhecimento, a mistura daquilo que é considerado verdadeiro porque nós nele acreditamos e aquilo em que nós acreditamos porque o consideramos verdadeiro. (Moscovici, 2003, p.339).

E conclui fazendo uma crítica velada, mas pertinente à Psicologia reducionista que se deixou influenciar pelos pressupostos da modernidade ao absolutizar a razão: "A pobreza do cognitivismo não é que ele ignore o sentido; ele deixa fora as crenças". (Moscovici, 2003, p.339).

A reflexão acima coloca-se como central para nossa discussão sobre o fenômeno da Pós-verdade, pois é exatamente nesse ponto que se coloca o grande desafio trazido pelas inúmeras questões que se apresentam nesse exato momento. Não conseguimos explicar de que modo, fatos ou realidades, considerados como indiscutivelmente verdadeiros e objetivos, passam a se diluir, como que a esboroar, levando multidões a aderir a determinadas verdades e a se comportar de acordo com essas "verdades". Constatamos que algo tido até agora como objetivo e verdadeiro - a verdade - assume um novo status, para além do puro lógico, cognitivo, racional e matemático. Seria esse o fenômeno da Pósverdade? Temos, talvez, de ser humildes e reconhecer que não damos conta de nossas crenças; elas fazem parte de nosso próprio ser, em grande parte elas nos constituem. Isso não significa que não possamos refletir sobre elas e nós mesmos. E nessa própria reflexão, nossas crenças nos acompanham. É a nossa própria condição humana.

O que estamos nos dando conta - e essa é a principal discussão dessa publicação - é o que estamos denominando como o fenômeno da Pós-verdade assumiu a verdade como crença; ela seria a verdade do fenômeno da Pósverdade. Há uma excrescência de crenças, elas tomaram conta. Não se dava mais importância às crenças. Para a modernidade só existia o matemático e o racional. Os filósofos do Iluminismo, no afã de dar conta e legitimar sua fé - pois ninguém consegue suprimir essa dimensão humana - instituíram um novo deus, a Deusa Razão, e a entronizaram no centro de Paris, bem em frente à Igreja de Notre Dame. E a hegemonia dessa deusa perdurou - e para alguns ainda perdura - por séculos. Foi a responsável pelo fim das grandes narrativas, sem se dar conta de que ela própria se transformou também em uma narrativa. E essa narrativa da modernidade também está se diluindo. No Manifesto Comunista (Marx \& 
Engels, 1848) Marx já intuiu esse novo espírito, ao afirmar que "tudo o que é sólido desmancha no ar." Temos a impressão que as crenças estão agora se vingando e estão retornando. Como o que Gilles Kepel (1994) discute em seu estudo The Revenge of God - A Vingança de Deus. Seria essa a nova verdade, a pós-verdade? Uma nova maneira de domar e de dar conta das crenças?

As motivações acrescentam à ideia de crenças e valores a dimensão da ação. Elas estão intrinsecamente ligadas aos valores e crenças. Pois, o que será esse algo que nos leva a agir? São, na verdade, essas realidades um tanto misteriosas, mas muito reais, que discutimos acima. Como também já acenamos, do mesmo modo que é difícil identificar nossas crenças e valores, é igualmente muito difícil identificarmos nossas motivações.

\section{Consciência e liberdade: a manipulação da consciência}

A discussão sobre consciência é um dos temas centrais à área da Psicologia. Intimamente relacionado à consciência está a questão da liberdade. Abordamos aqui esse aspecto crucial e central à temática que estamos enfrentando.

Há muitas compreensões do que seja consciência. Numa perspectiva psicossocial a consciência é assumida como "o quanto de respostas conseguimos às perguntas: quem sou eu?", a pergunta fundamental que atravessa todos os tempos de todas as sociedades humanas; e a pergunta: "por que as coisas que nos rodeiam são assim?" Assume-se, com isso, que quanto mais respostas conseguimos a essas perguntas, mais consciência nós temos. Ela é um processo, uma busca interminável das razões de por que fazemos o que fazemos. A tomada de consciência é, pois, um processo infinito: nunca chegaremos a atingir um entendimento completo de quem somos e do mundo que nos rodeia.

A estratégia pedagógica para levarmos as pessoas ao crescimento em consciência é fazer a pergunta, para as pessoas refletirem.
Para Freire (1979), a característica essencial do processo pedagógico é fazer a pergunta. E, à medida que se conseguem respostas a essa pergunta, vai-se ampliando a consciência, processo que ele denomina de conscientização.

Como se poderia entender a liberdade nesse contexto? Liberdade é um conceito complexo e multifacetado. Uma maneira realista e esclarecedora de se refletir sobre ela e dar-lhe uma dimensão prática é relacioná-la à noção de consciência que colocamos acima e mostrar que liberdade está intrinsecamente ligada à consciência. Nesse sentido, à medida que crescemos em consciência, vamos também crescendo em liberdade. Já porque ninguém pode ser considerado livre, se não tem consciência. É o caminho que desenvolve Paulo Freire (1979), quando discute esse processo em um livro que significativamente se chama de Educação como Prática da Liberdade. Nesse sentido, à medida que pensamos e buscamos respostas às questões que nos cercam, caminhamos em direção a uma sempre maior liberdade, ela também como um processo e uma prática intermináveis.

Acenamos, aqui, a um problema para o qual retornamos adiante, mas que é desafiador. Vivemos uma ambiência em que se torna cada vez mais difícil parar para pensar A questão que se coloca é, então: o quanto de consciência existiria em pessoas sujeitas a milhares, ou milhões, de informações repetidas constantemente, com inúmeras conotações de prazer, alegria, gozo, satisfação de diferentes desejos, seduções, ou mesmo ameaças, medo, etc. despejadas 24 horas por dia, momento a momento? Nessa avalanche de informações e no bombardeio incessante de mensagens, quanto tempo, ou que espaço nos sobra para podermos refletir? Num exemplo trazido por Halpern (2017), ao comentar a campanha de Donald Trump ela escreve

Todo dia..a campanha veiculava 40 a 50 mil variações de seus anúncios, testando seu impacto em diferentes formatos, com ou sem subtítulos, anúncios estáticos ou em vídeo, entre outras pequenas diferenças. No dia do 
terceiro debate presidencial em outubro, o time veiculou 175 mil variações. (p.3).

Permanece a pergunta: num mundo povoado e repleto de sinais, de bits, sobra ainda tempo para pensar e se perguntar as razões de fazermos o que fazemos? Os sinais dos tempos hoje é que vivemos um tempo de sinais. A grande novidade é que as novas tecnologias se desenvolveram de maneira espantosa e começaram a trabalhar na manipulação dos bits, pois o mundo se transformou em bits: nossa realidade é construída de bits. As novas tecnologias, a Inteligência Artificial, o uso de robôs que substituem seres humanos para divulgação de mensagens nas redes sociais vinte e quatro horas ao dia, a construção de algoritmos personalizados, todo esse instrumental se especializou em trabalhar empírica e matematicamente com números, com bits.

\section{A construção da subjetividade}

O conceito de subjetividade é um conceito caro aos psicólogos/as. Como não podia deixar de ser, ele também é entendido de diferentes modos, com diferentes conotações, pelas pessoas que o empregam. Explicamos aqui a maneira como o entendemos.

Assumimos o ser humano como sendo pessoa=relação, bem diferente do que se entende por indivíduo. Relação (ordo ad aliquid), é um direcionamento intrínseco de um ser em direção a outro: é singular, mas para ser, necessita intrinsecamente de outro. Já indivíduo (indivisum in se, divisum a quolibet alio), como o entende a filosofia liberal, a partir do cartesianismo, é alguém que é singular, sim, mas que não tem nada a ver com outro(s).

Que seria, então, subjetividade? Se pararmos um instante e nos perguntarmos quem nós somos, como nos construímos e constituímos, podemos constatar que somos, na verdade, algo como uma soma total das relações que estabelecemos em nossa vida, desde o primeiro momento, isto é, desde a primeira relação que constituímos ou que foi conosco estabelecida.

É a partir dessas considerações que apresentamos um entendimento do que se vai entender por subjetividade. Há inúmeros termos que são empregados, por diferentes autores, ao discutir realidades que, de um modo ou outro, pretendem mostrar a constituição psíquica do ser humano, como identidade, personalidade, entre outras. Cada um pode fazer uso do termo que quiser, com a condição de dizer o que vai entender com ele.

No caso em questão, cremos que se pode dar conta desse mistério que somos nós, lançando mão de dois conceitos: o conceito de subjetividade e o de singularidade. Entendemos singularidade como aquela dimensão do ser humano que pressupõe sermos um, únicos, irrepetíveis. Por quê? Porque, ao estabelecermos uma relação, recortamos dela pedaços específicos, pessoais, próprios e com eles vamos construindo a colcha de retalhos do que designo agora como nossa subjetividade. E tomo subjetividade como sendo, por assim dizer, o conteúdo dessas relações. Nesse sentido, nossa subjetividade é constituída também pelos outros, pelas relações que com eles estabelecemos. Desse modo nossa subjetividade é sempre social. Somos fundamentalmente singulares, mas sempre construídos a partir de outros, é assim que entendemos subjetividade, a partir do ser humano assumido como pessoa = relação .

Ajuda a justificar o termo subjetividade como tomado aqui, recorrendo a sua dimensão etimológica. Subjetividade vem de sub-jectum, do latim: $s u b$, o que está debaixo e jacere, estar deitado: ela seria então aquele lastro que permanece em nós no ato e após estabelecermos relações com qualquer um outro(s), pessoas ou objetos; algo que se torna como que o ponto de referência, ou como um suporte, no qual vamos ancorando nossas relações. É o que entendemos quando fazemos referência ao sujeito de uma frase, se digo, por exemplo, que Ana é bonita, estou, de certo modo, ancorando no suporte Ana, o verboé e o predicado bonita. O sujeito é o ponto de 
referência e subjetividade é um substantivo abstrato que recolhe e sintetiza todos esses traços-relaçõos.

O social, como o entendemos aqui, é tomado como relação; dá conta da pluralidade de dimensões que ele comporta, mas não se transforma numa realidade única, fechada. É nessa última acepção que a subjetividade é sempre social (Gonzalez Rey, 2004): ela é um processo em contínua construção onde a relação outro está sempre presente: somos a soma total de nossas relações (Marx \& Engels, 1989).

É a partir dos conceitos da Psicologia discutidos acima - valores, crenças, motivações, consciência, liberdade e subjetividade - e do entendimento que deles assumimos, passamos agora a contrapô-los à discussão feita sobre Pós-verdade. Nossa proposição é de que se pode falar, hoje, do surgimento de uma subjetividade digital, com objetivos específicos de transformar os seres humanos em objetos de interesse um tecnocapitalismo financeiro internacional. Parece ser uma hipótese arriscada, mas desejamos prevenir e argumentar que numa era Pós-verdade, com a parafernália das novas tecnologias, principalmente na área da comunicação, e com o auxílio da Psicologia, torna-se possível construir valores e subjetividades que assemelhem os seres humanos a robôs, diminuindo e ferindo fortemente sua consciência e liberdade.

\section{Subjetividades digitais e tecnocapitalismo}

A enorme importância (econômica, política, militar etc.) que a Psicologia passou a ter no mundo das novas tecnologias digitais e, por extensão, com o desenvolvimento do fenômeno da Pós-verdade, deve-se a um acaso e a uma surpresa. Em 2014, em Cambridge, o psicólogo Michael Kosinski, com alguns parceiros do Centro de Psicometria, criou um aplicativo chamado MyPersonality, para medir e analisar características psicológicas individuais que, de modo geral, através do modelo dos Big Five, isto é, de cinco traços que, segundo esse modelo, seriam centrais à constituição da personalidade. Esperava que alguns amigos preenchessem os questionários $\mathrm{e}$, de forma rápida e surpreendente eram centenas, milhares e depois milhões que lhes revelavam suas crenças, sentimentos, comportamentos. E assim esses estudantes se viram diante do maior banco de dados sobre personalidade da história.

Esses resultados começaram a ser comparados com outros dados digitais, como o que os participantes curtiam, o que compartilhavam, o que postavam no Facebook, de início. Mas depois passaram a buscar em outras mídias, como pesquisas no Google, mensagens no Twitter, WhatsApp etc. Identificavam, assim, o gênero, a idade, o endereço, muitas vezes até a profissão e outras informações dos respondentes. Surgiu assim a possibilidade de construir perfis psicológicos íntimos das pessoas e compará-los entre si. E aconteceu algo impensável: a coleta de dados, tão difícil de ser feita antes através de questionários e entrevistas, passou a ser gratuita. Ingenuamente, senão astutamente, a maioria dos incautos ficava todo $\mathrm{o}$ dia fornecendo dados para construir, sem que eles soubessem, seu algoritmo: aquele imenso repositório onde são armazenados os milhões, ou mesmo bilhões de informações a seu respeito. $\mathrm{Na}$ verdade, toda vez que alguém curte, partilha, posta, comenta, lê um comentário, fala no WhatsApp, aprecia uma foto nas diferentes mídias sociais, está oferecendo dados preciosos para seu algoritmo.

A variedade e a eficácia das estratégias que podem ser usadas com o uso das informações das mídias foram mostradas pela equipe de Kosinski: com uma média de 68 curtidas por usuário, era possível prever sua etnia com $95 \%$ de precisão, e sua orientação sexual com $88 \%$ de precisão. Para o caso dos EUA, podia-se prever em $85 \%$ dos casos se era democrata ou republicano. Para fins de propaganda e marketing não se necessita mais que tal proporção para se poder apostar em determinadas decisões.

Essa descoberta fugiu das mãos do psicólogo e caiu nas mãos de empresas que de 
imediato começaram a pensar em ganhar lucro, como a Cambridge Analytica, e sua controladora, a Strategic Communication Laboratories (SCL), entre outras. A Cambridge Analytica foi a responsável pela campanha da eleição de Trump, como também propaganda pela saída da Inglaterra da Comunidade Européia, o Brexit.

Como prova de que não estamos imaginando coisas, vejamos o que aconteceu no início do mês de maio de 2018 (El Pais, 2018): a Cambridge Analytica, pivô da polêmica sobre o Facebook, foi obrigada a fechar. As multas que Mark Zuckerberg, dono do Facebook e de outras mídias sociais já tinha pago, nessa data, pelo fato de ter repassado mais de 80 milhões de algoritmos à Cambridge Analytica, já passavam de 200 bilhões de dólares. E para cada usuário que se sentisse lesado por ter tido seus dados revelados, a multa era de ao redor de 40 mil dólares.

O emprego das informações midiáticas torna-se muito relevante para previsões também no campo da política e da segurança (Sadin, 2015). Tal propensão ganhou maior importância depois dos atentados de setembro de 2011, levando as agências de informação a antecipar possíveis dificuldades, desenhando cenários de possíveis ações políticas ou militares.

a SCL forneceu avaliações de inteligência para firmas (empreiteiras) americanas de defesa para o Iran, Líbia e Síria, e também desenvolveu campanhas assim chamadas de influência para a Otan no Afeganistão [...] através de análise de audiênciaalvo para o Departamento de Defesa dos EUA, identificando quem poderia ser susceptível de propaganda americana. (Halpern, 2017, p.4).

$\mathrm{Na}$ era dos Grandes Números (Big Data), dos Algoritmos, da matemática computacional, da Inteligência Artificial, todas essas novas tecnologias, foram e estão sendo empregadas para identificar e analisar milhões de dados de fontes públicas, corretores com informações comerciais, além das mídias sociais. Através de refinadas análises pode-se saber quem votaria, ou não, em determinado candidato; quem teria alguma chance de ser persuadido. Criam-se segmentos, por exemplo, de mães que estão preocupadas com a violência e a segurança; de estudantes que estão com dívidas nos bancos etc. E para cada um são criadas mensagens personalizadas, para depois se medir que tipo de mensagens teve mais sucesso (Halpern, 2017).

As evidências de que isso já está sendo feito são comprovadas por inúmeros exemplos de nosso cotidiano, como quando mencionamos, ou postamos algo nas redes sociais, quando solicitamos informações, adquirimos algum produto, compramos uma passagem etc. Dentro de poucos instantes já começamos a receber informações relacionadas com nossas postagens. Há programações para isso, que podem ser mais ou menos diretas, oferecidas com mais ou menos frequência, com maior ou menor intensidade, de forma estática ou em vídeos, com diferentes cores etc. Um estudo de Dias, Varon, Teixeira, e Felizi (2017) é extremamente ilustrativo. Uma mulher soube pelas mídias de que estava grávida e o mercado online já comemorava a notícia enviando mensagens com ofertas de produtos destinados a mães e bebês. Até há pouco era uma profissional que gostava de comprar; agora é uma futura mãe, e seu algoritmo passou de US\$ 0,10 , de uma pessoa normal, para US\$ 1,50 : foi multiplicado por 15 . As mensagens e propagandas são agora dirigidas a uma pessoa que está num processo de reconstrução de sua identidade, com o nascimento do filho. E o marketing sabe disso. Faz parte do processo de perfilamento (profiling) procurar grupos com padrões de comportamento para tentar enquadrar as pessoas, entregando o que elas possivelmente querem, ou o que supostamente querem.

A partir dessas evidências, podemos perguntar: onde entramos nós nesse quadro? Difícil negar somos parte integrante dele. Corremos o risco de nos tornarmos presas e sermos capturados por essa imensa e misteriosa parafernália de informações. Dizendo mais 
claramente: até que ponto conseguiremos continuar conscientes desse processo e garantir nossa liberdade? Até que ponto nossa subjetividade não estaria sendo impregnada e mesmo condicionada por essa atmosfera e ambiência digital, nessa era de Pós-verdade?

É oportuno aqui aprofundar o conceito de algoritmo. Se tradicionalmente ele é entendido como uma regulamentação específica, intrinsecamente nele inserida, para que execute tarefas pré-assinaladas sobre determinados dados, em geral numéricos, em função de determinado fim, ele está sendo agora empregado para outros fins, que são: como interpretar determinadas situações e até mesmo tendo uma capacidade de sugerir determinadas soluções para se alcançar resultados desejados. Alguns pensadores desse momento histórico vão ainda mais além e afirmam ser ele capaz de até tomar decisões de maneira autônoma.

O ensaísta e filósofo Eric Sadin, um dos mais argutos e mais críticos analistas do nosso mundo digital, comenta que:

Isso se constitui num acontecimento tecnológico e epistemológico de grande importância, pois esse tipo de algoritmo não se contenta apenas em executar comandos, mas tende a influenciar nossas decisões, a nos encorajar a agir de tal modo e não de outro, em função de interesses não imediatamente manifestos. (2015, p.74).

Defrontamo-nos aqui e agora com um novo fenômeno, com uma ação-relação com outras características: diante da avalanche incontrolável de contínuas informações, diante da dificuldade, ou quase impossibilidade, de nos determos e tomarmos consciência de tudo o que chega até nós; diante do caráter insinuante, persuasivo, sedutor e pervasivo dessas mensagens; e, principalmente, diante da aparente naturalização desse fenômeno, somos quase que tomados de assalto, de maneira pacífica e silenciosa, em grande parte inconsciente ou semiconsciente. Somos como que anestesiados e nos movemos passivamente em direções que dificilmente poderiam ser consideradas plenamente livres. Estaríamos passando de um algoritmo condicionante a um totalitário?

O que atualmente assume uma forma totalizante é que, com a digitalização de nossas existências, mais e mais nossos gestos são orientados por algoritmos que nos fazem adotar comportamentos, não de modo coercitivo, mas sob uma forma incitativa através da estimulação do desejo. E isso faz com que o fenômeno seja difícil de ser identificado e percebido, como diz Sadin (2015a, p. 74):

Pois nós somos colocados sob um regime da sedução induzido pela ergonomia fluida das interfaces da dimensão lúdica das aplicações, tanto quanto que pela intuição algorítmica capaz de nos sugerir recomendações personalizadas. A incitação algorítmica não nos força a nada, ela cria um sentimento de evidência. Ela surge quase que de uma ordem epifânica para nos revelar continuamente aquilo de que supostamente estaríamos necessitando (ênfase no original).

Passamos assim a ter novos assistentes digitais personalizados com a finalidade de acompanhar-nos da melhor maneira possível e de modo automatizado ao longo de nosso dia a dia. Novos parceiros, anônimos, silenciosos, mas extremamente eficazes na construção e reconstrução de nossa subjetividade. Somos frutos da trama de um outro que está por detrás de nós e se apodera, todos os dias e com a nossa cumplicidade, da nossa essência humana.

A isso Sadin (2017b) chamou de inocência culpável. Somos levados a um processo de naturalização da realidade onde as tecnologias digitais se desenvolvem com extraordinário poder sem que disso nos demos conta. Banalizamos sua penetração nos assuntos humanos e permitimos que adentrem nossa vida, considerando-as como algo normal com a criação dessa nova ambiência 
naturalizada. Estabelece-se um cerco onde os possíveis parceiros são demarcados, estabelecendo-se ao redor das pessoas um círculo fechado. O Facebook é um bom exemplo. Nossos amigos são estabelecidos através de critérios de aceitação - ou de rejeição - dos quais não temos plena consciência, nem plena liberdade de escolha. Através de um número incontável de informações, e hoje até mesmo com o emprego de robôs que substituem os comunicadores, são estabelecidas estatísticas que vão determinar quais são nossos amigos, ou inimigos e de que notícias ou mensagens somos dignos. Quando se pensa que esse cerco foi rompido, entramos num novo círculo, com o acréscimo de novos critérios, participando de novos ambientes, esses também criados e moldados pelas novas tecnologias da Inteligência Artificial, que se reservam o direito de apresentar as novidades que merecemos ver, ouvir e sentir. A atração pelo novo nos faz caminhar nesse círculo totalizante e totalizador, sem permitir que transponhamos as barreiras que estabelecem nossos horizontes (Sadin, 2009; 2011).

Poder-se-ia falar de um novo tipo de lavagem cerebral? Se a tradicional consistia no isolamento das pessoas fisicamente, sem contato com ninguém, além do permitido pelos controladores (Guareschi, 1990), as novas mídias, com estratégias análogas, conseguem o controle através da sugestão, da persuasão, quando não de maneira subliminar. Muitos, principalmente os jovens, vão se tornando ansiosos, até mesmo a se sentir culpados, por perderem o timing de poder saber sobre determinados acontecimentos, ou de assistir a programações estrategicamente anunciadas. É sintomático observar como grupos de pessoas, reunidas num mesmo local, muitas vezes permanecem singularizadas, isoladas, cada uma com sua máquina, sua parceira preferida. Sofremos continuamente um ataque cada vez mais penetrante e agressivo dessas novas estratégias que, além de cerebrais, são virais, vitais, motivacionais, com influências sobre a vontade, os desejos, as motivações que levam as pessoas a agir: comprar, votar, divertir-se consumir seja o que for.
Ao chegar ao final dessas reflexões parece-me indispensável acenar para um componente novo, crucial, sobre o impacto que os artefatos tecnológicos podem trazer à vida humana. Retomo reflexões de Sadin (2013) em que traça um diagnóstico do que ele denomina de administração digital da vida humana. Segundo ele, com a criação de uma subjetividade digital estamos chegando à era de um anti-humanismo radical. E isso faz pleno sentido, pois como vimos, partimos do pressuposto que o ser humano se caracteriza por sua consciência, construída a partir da reflexão na busca de respostas que momento a momento vai conseguindo à pergunta sobre quem ele é; e que a liberdade é um processo ligado a esse crescimento em consciência - só é livre quem tem consciência. Poderíamos perguntar: quem estaria lucrando com a diminuição de nossa consciência e com a profunda agressão a nossa liberdade?

Uma análise mais cuidadosa e global mostra que toda a estratégia empregada pelo mundo digital se resume, ao final de tudo, a satisfazer os objetivos centrais e permanentes de um novo capitalismo, denominado de tecnocapialismo ou tecno-liberalismo. $\mathrm{Na}$ necessidade de garantir a hegemonia desse novo Modo de Produção Capitalista faz-se uso de todas as táticas e estratégias do extraordinário desenvolvimento das novas tecnologias, principalmente no campo da comunicação. Esse avanço extraordinário, com sua criatividade, leva à ampliação, aprofundamento e fortificação de um novo tipo de modo de vida. Mas as estratégias empregadas trazem consigo e pressupõem conotações valorativas, éticas. $\mathrm{O}$ que se pretende agora é chegar à mercantilização integral da vida; em outras palavras, o objetivo subjacente é tentar reduzir a vida e o ser humano a um objeto eternamente mercantil.

Vivemos ainda, quer queiramos ou não, sob a égide do capitalismo. E o que sempre o identificou foi a busca do lucro, do enriquecimento, seu objetivo intrínseco e essencial. $\mathrm{O}$ aspecto novo, contudo, é que o objeto de dominação e exploração hoje visado é muito mais sério e crucial: é o próprio ser 
humano, com seus desejos e sua subjetividade, quando não com prejuízo de sua consciência e sua liberdade, que estão em jogo. Na busca de lucro esse novo capitalismo tem a capacidade de mercantilizar todos os momentos da existência humana. É o novo estágio do capitalismo liberal.

Vejamos o Google. Ele nasceu com a importante contribuição na busca das palavraschave, mas agora está se alastrando no mercado da saúde, da educação, está presente com o Google Car, Google Home - a casa conectada - e assim por diante. Não apenas o Google, mas toda indústria digital, anseiam conquistar a vida toda das pessoas. Como vimos, isso tudo começa pelo conhecimento refinado dos comportamentos de cada indivíduo, de maneira evolutiva, detalhada e em escala global. Como diz Sadin (2017a, Eis a entrevista, para. 4) "esse é o modelo e, paradoxalmente, esse modelo é celebrado por toda a sociedade quando, na realidade, seu efeito maior está em reduzir a vida e o ser humano a um objeto eternamente mercantil e condenado eternamente a oferecer o testemunho de sua vida".

A pretensão, nesse novo estágio do capitalismo, consiste em não deixar nenhum espaço da existência vazio e o propósito é lançar-se à conquista integral da vida. Com sensores colocados ao longo de toda a superfície da existência pode-se chegar a rentabilizar, a monetarizar todo $\mathrm{O}$ conhecimento comportamental. Toda vida humana passa a ser mera mercadoria. Por exemplo, uma balança conectada não me daria apenas meu peso, mas também, por meio de aplicativos, a inclusão, a oferta, em função dos meus estados, de complementos alimentares ou oferta de programações específicas de esporte e lazer. Através de objetos conectados estaria a possibilidade de penetrar em nossos comportamentos e sugerir ofertas, bens ou serviços adaptados a cada perfil e a cada instante da vida cotidiana. Ali onde o mercado capitalista encontrar um espaço vazio, vai introduzir ofertas, sugestões, propostas de compras.
Nem sequer grupos vulneráveis e de risco escapam a tais investidas da mídia. Um artigo publicado por Marina Pita (2017) comenta o vazamento de um documento feito pelo jornal Australian, dois anos depois de o fato estar acontecendo, em que o Facebook se vangloriava de poder monitorar posts e fotos em tempo real para determinar quando um jovem se sentiria estressado, derrotado, ansioso, nervoso, estúpido, fracassado, idiota. O trágico desse fato é que esse serviço foi feito para um dos maiores bancos da Austrália. Constata-se, aqui, como informações sobre a situação emocional de jovens e adolescentes estão sendo usadas para fins econômicos e para lucro de grandes corporações. Até mesmo as vulnerabilidades, fragilidades, inseguranças das pessoas são exploradas com o fim de vender e lucrar. Nossos acessos às diferentes mídias são continuamente monitoradas a partir de diferentes critérios, sendo o mais central descobrir o perfil comercial de consumo. Mesmo um perfil político é buscado dentro da perspectiva do mercado, da vantagem econômica do lucro.

A busca insaciável do lucro é o ethos que, em última análise, move toda essa parafernália tecnológica. $\mathrm{Na}$ conquista dos desejos e motivações está a guerra industrial presente e futura. Há uma visualização cada vez mais profunda do comportamento humano nos perfis digitais e essa informação é o que se busca vender, em plataformas, a companhias de todo o mundo.

Com a facilidade de se conseguirem milhões de informações, a respeito de milhões de pessoas, o principal objetivo das grandes corporações que empregam mídias sociais não é produzir um saber específico sobre um indivíduo particular, mas usar esse conjunto de informações para agir sobre o exército de similares, como diz Bruto (2013). Os diferentes perfis são construídos e atuam como categorização de conduta, visando inclusive à simulação de comportamentos futuros.

Levados pela fascinação digital, não nos damos conta e não temos plena consciência de um poderoso movimento que anseia conquistar 
nossas existências e imiscuir-se em cada âmbito da vida. Assim comenta Sadin (2017b):

Praticamos uma espécie de inocência culpável, a partir do momento em que não nos compromete a responsabilidade de defender princípios que regem nossa existência há séculos, como a autonomia de juízo, a livre decisão e a deliberação individual e coletiva, capacidades que serão erradicadas em menos de uma geração. (Ênfase nossa). (Eis a entrevista, para. 1).

Um pesadelo que nos assombra é que há, ainda, novas dimensões que são possíveis e não sabemos se talvez não estejam já em execução. Ao menos não temos ainda conhecimento e consciência disso, mas podemos entrever possíveis consequências caso se concretizarem. Como assinala Sadin em outra publicação $(2015 b$, p.73), "O tecnoliberalismo procura explorar cada sequência da existencia", e lança-se à conquista integral da vida. O que se pretende assegurar agora é o que há de mais humano nos seres humanos: sua capacidade de tomarem consciência e, consequentemente, de se tornarem mais livres e autenticamente responsáveis.

Desse modo, a Internet, objetos conectados, a inteligência artificial e uma enorme gama de aplicativos nos são apresentados como desenvolvimento da humanidade. Tais tecnologias, supostamente facilitadoras, podem atentar contra o que há de mais central no ser humano, o que através dos séculos se denominou como sendo o tripé da dignidade humana: consciência, liberdade, responsabilidade. É nesse sentido que Sadin (2017b) alerta sobre a possibilidade de estarmos lidando com práticas que poderiam levar a um anti-humanismo radical.
O meio ambiente tecnológico aponta para uma organização automatizada, ou algorítmica, de um número cada vez maior de setores da sociedade. Esse é um fenômeno já corriqueiramente constatável cujo exemplo é o de empresas pilotadas pelos dados, o que se denominou de Data Driven. O passo seguinte agora, a partir dessas tecnologias, seria a aplicação desse conjunto de tecnologias no próprio ser humano, onde se procura identificar suas ações, até mesmo em tempo real, e novas ações vão sendo sugeridas a partir das já realizadas, com sucesso ou não.

\section{Conclusão}

Através da internet o nível de detalhamento e poder persuasivo das propagandas vai a níveis cujas consequências ainda são desconhecidas. E isso só é possível porque há ferramentas bem sofisticadas de monitoramento que acompanham praticamente tudo o que se faz online.

A partir da década de 90, as tecnologias da informação propiciaram o acesso de milhões de pessoas a textos, imagens e sons: foi o que se denominou de a era do acesso. Acontece, contudo, que essas conquistas não pararam de se ampliar e estão passando da digitalização de sons, imagens e textos, para a era da digitalização da própria vida. Estamos chegando à era dos sensores, dos objetos conectados e da inteligência artificial.

Um grande dilema que a Psicologia coloca à questão das novas tecnologias e ao fenômeno da Pós-verdade, poderia ser enunciado assim: até que ponto permanecemos livres? A liberdade implica a consciência. $\mathrm{Na}$ medida em que perdemos a capacidade de avançar em consciência, vamos também perdendo porções de nossa liberdade. Essa é, claramente, uma questão ética. Que futuro nos aguarda?

\section{Referências}

\author{
Alterman, E. (2004). When Presidents Lie: A \\ History of Official Deception and Its
}

Consequences. United States of America:

Penguin Group. 
Amon, D. (2017). O contexto sócioantropológico da pós-verdade. In P. Guareschi, D. Amon, \& A. Guerra (orgs.), Psicologia, Comunicação e Pós-verdade (pp. 25-52). Porto Alegre: Evangraf.

Amon, D., \& Idiart, S.A. (2017). Linguagem: uma abordagem histórica e conceitual para a compreensão e crítica à Pós-verade. In P. Guareschi, D. Amon, \& A. Guerra (orgs.), Psicologia, Comunicação e Pós-verdade (pp. 53-81). Porto Alegre: Evangraf.

Barthes, R. (2011). The Preparation of the Novel: Lecture Courses and Seminars at the Collège de France, 1978-1979 and 1979-1980. Nova Iorque: Columbia University Press.

Bruto, F. (2013). Máquinas de Ver, Modos de Ser - vigilância, tecnologia e subjetividade. Porto Alegre: Sulina.

Dias, T., Varon, J., Teixeira, L., \& Felizi, N. (2017, 11 de julho). Como funciona $o$ lucrativo mercado dos estereótipos online. Recuperado de https://motherboard.vice.com/pt br/article/ a3djgz/como-funciona-o-lucativo-mercadode-estereotipos-online Acesso em 4 de setembro de 2017.

Eco, U. (1976). A Theory of Semiotics. Bloomiongton: Indiana University Press.

El Pais (2018). Pivô da polêmica sobre Facebook, Cambridge Analytica fecha. https://brasil.elpais.com/brasil/2018/05/02/i nternacional/1525285885_691249.html.

English Oxford Living Dictionaries, (s.d.), Word of the Year 2016 is... Recuperado de https://en.oxforddictionaries.com/word-ofthe-year/word-of-the-year-2016 Acesso em 15 de agosto de 2017.

Freire, P. (1979). Educação como Prática da Liberdade. Rio de Janeiro: Paz e Terra.

Gonzalez Rey, F. (2004). O Social na Psicologia e a Psicologia Social: a emergência do sujeito. Petrópolis: Vozes.

Guareschi, P. (1990). Igreja da Unificação. In L. Landim (org) Sinais dos Tempos (pp.245-252). Rio de Janeiro: ISER.

Guareschi, P. Amon, D., \& Guerra, A. (2017). Psicologia, Comunicação e Pós-verdade. Porto Alegre: Evangraf.
Guerra, A., \& Barbosa, C. (2017). Crítica e Pós-Verdade. In P. Guareschi, D. Amon, \& A. Guerra (orgs.), Psicologia, Comunicação e Pós-verdade (pp. 101-160). Porto Alegre: Evangraf.

Halpern, S. (2017, June 8). How He Used Facebook to Win. In The New York Review of Books, June 8, 2017 Issue.

Hartford, T. (2017, 10 de março). Na era da pós-verdade, os fatos precisam de defensores. In Folha de São Paulo. Recuperado de https://www1.folha.uol.com.br/mundo/201 7/03/1865256-na-era-da-pos-verdade-osfatos-precisam-de-defensores.shtml.

Jovchelovitch, S. (2007). Os Contextos do Saber: representações, comunidade e cultura. Petrópolis: Vozes.

Kepel, G. (1994). The Revenge of God. Cambridge: Polity Press.

Keyes, R. (2004). The Post Truth EraDishonesty and Deception in Contemporary Life. Nova Iorque: St Martin Press.

Marx, K., \& Engels, F. (1848). O Manifesto Comunista. Versão para eBooks Ridendo Castigat Mores, eBooks Brasil.com.

Marx, K. \& Engels, F. (1989). Teses sobre Feuerbach. In K. Marx, \& F. Engels, $A$ Ideologia alemã (Introdução). São Paulo: Martins Fontes.

Moscovici, S. (2003). Representações Sociais: investigações em psicologia social. Petrópolis: Vozes.

Pita, M. (2017). Facebook negocia dados de milhões de jovens emocionalmente vulneráveis. In Carta Capital. Recuperado de

https://www.cartacapital.com.br/blogs/inter vozes/facebook-negocia-dados-de-milhoesde-jovens-emocionalmente-vulneraveis. Acesso em 11 de setembro de 2017.

Priolli, G. (2017, 13 de janeiro). A era da pósverdade. In Carta Capital. Recuperado de https://www.cartacapital.com.br/revista/933 la-era-da-pos-verdade. Acesso em 22 de abril de 2017.

Reis, H. (2017, 10 de janeiro). O mundo da pós-verdade. In Homero Reis. Recuperado 
de http://homeroreis.com/o-mundo-da-posverdade/. Acesso em 25 de abril de 2017.

Sadin, É. (2009). Surveillance globale:

Enquête sur les nouvelles formes de contrôle. Climats/Flammarion.

Sadin, É. (2011). La Société d'anticipation. L'Echappée (traduzida para o espanhol em 2013. Buenos Aires: Editora Caja Negra).

Sadin, É. (2015a) La vie algorithmique: Critique de la raison numérique. L'Échappée.

Sadin, É. (2015b). Le techno-capitalisme cherche à exploiter chaque séquence de l'ésistence. Sociétés 2015/3 (n.129), p.7377). Entrevista concedida a Pierric Marissal.

Sadin, É. (2016). La silicolonisation $d u$ monde: L'irrésistible expansion $d u$ libéralisme numérique. L'Échappée.
Sadin, É. (2017a). O tecnoliberalismo lança-se à conquista integral da vida. In $I H U$ Newsletter - Instituto Humanitas Unisinos. Entrevista de Eduardo Febbro, publicada por Página/12, Buenos Aires, 23-06-2017,

Sadin, É. (2017b). A Era do Anti-Humanismo Radical. In IHU Newsletter - Instituto Humanitas Unisinos.Entrevista ao jornal argentino Rio Negro, 27 de junho de 2017 Tatiana, D., Varon, J., Teixeira, L, e Felizi, N. (2017). Como funciona o lucrativo mercado de estereótipos online.

Recuperado de https://motherboard.vice.com/pt br/article/ a3djgz/como-funciona-o-lucrativomercado-de-estereotipos-online Acesso em 11 de setembro de 2017.

Wittgenstein, L. (1992). Tractatus LogicoPhilosophicus. S.Paulo: Martins Fontes.

\section{Dados sobre o autor:}

- Pedrinho Guareschi: Graduado em Filosofia pela Faculdade de Filosofia Imaculada Conceição (1969), e em Teologia pelo Instituto Redentorista de Estudos Superiores de SP (1964), Pósgraduação em Sociologia pela PUCRS (1965), graduação em Letras pela Universidade de Passo Fundo (1968), mestrado em Psicologia Social - Marquette University Milwaudee (1973), doutorado em Psicologia Social - University Of Wisconsin At Madison (1980). Pós-doutorado no departamento de Ciências Sociais na Universidade de Wisconsin (1991) e na Universidade de Cambridge (2002). Pós-doutorado na Università degli Studi La Sapienza, Roma, no departamento de Psicologia (2014/15). De 1969 a 2009 foi professor no Programa de Pósgraduação em Psicologia na PUCRS. Atualmente é professor convidado da Universidade Federal do Rio Grande do Sul e Conferencista Internacional. 